\title{
Skeletal Muscle Membrane Lipid Composition Is Related to Adiposity and Insulin Action
}

\author{
David A. Pan, ${ }^{\ddagger}$ Stephen Lillioja, ${ }^{5}$ Michael R. Milner, ${ }^{\$}$ Adamandia D. Kriketos, ${ }^{\ddagger}$ Louise A. Baur, ${ }^{\ddagger}$ Clifton Bogardus, ${ }^{\$}$ \\ and L. H. Storlien" \\ ${ }^{\ddagger}$ Department of Endocrinology, Royal Prince Alfred Hospital, Sydney NSW 2050, Australia; ${ }^{\circledR}$ Clinical Diabetes and Nutrition Section, \\ NIDDK NIH, Phoenix, Arizona 85016; and "Department of Biomedical Science, University of Wollongong, \\ Wollongong NSW 2522, Australia
}

\begin{abstract}
The cellular basis of insulin resistance is still unknown, however, relationships have been demonstrated between insulin action in muscle and the fatty acid profile of the major membrane structural lipid (phospholipid). The present study aimed to further investigate the hypothesis that insulin action and adiposity are associated with changes in the structural lipid composition of the cell. In 52 adult male Pima Indians, insulin action (euglycemic clamp), percentage body fat (pFAT; underwater weighing), and muscle phospholipid fatty acid composition (percutaneous biopsy of vastus lateralis) were determined. Insulin action (highdose clamp; MZ) correlated with composite measures of membrane unsaturation ( $\% \mathrm{C20}-22$ polyunsaturated fatty acids $[r=0.463, P<0.001]$, unsaturation index $[r=-0.369$, $P<0.01]$ ), a number of individual fatty acids and with $\Delta 5$ desaturase activity $(r=0.451, P<0.001)$. pFAT (range $14-53 \%$ ) correlated with a number of individual fatty acids and $\Delta 5$ desaturase activity $(r=-0.610, P<0.0001)$. Indices of elongase activity $(r=-0.467, P<0.001)$, and $\Delta 9$ desaturase activity $(r=0.332, P<0.05)$ were also related to pFAT but not insulin action. The results demonstrate that $\Delta \mathbf{5}$ desaturase activity is independently related to both insulin resistance and obesity. While determining the mechanisms underlying this relationship is important for future investigations, strategies aimed at restoring "normal" enzyme activities, and membrane unsaturation, may have therapeutic importance in the "syndromes of insulin resistance." (J. Clin. Invest. 1995. 96:2802-2808.) Key words: dietary fats • euglycemic clamp • body composition • elongase activity $\bullet$ desaturase activity
\end{abstract}

\section{Introduction}

Impaired insulin action (insulin resistance) is central to a cluster of prevalent diseases including non-insulin-dependent diabetes

Aspects of these data were reported at the 1993 meeting of the North American Association for the Study of Obesity.

Address correspondence to David A. Pan, Department of Biomedical Science, University of Wollongong, Wollongong NSW 2522, Australia. Phone: 42-213 881; FAX: 42-214 096. S. Lillioja's present address is Diabetes Centre. Southwestern Sydney Clinical School. University of New South Wales, PO Box 103 Liverpool NSW 2170 Australia.

Received for publication 5 December 1994 and accepted in revised form 7 September 1995.

J. Clin. Invest.

(C) The American Society for Clinical Investigation, Inc.

0021-9738/95/12/2802/07 \$2.00

Volume 96, December 1995, 2802-2808 mellitus (NIDDM), ${ }^{1}$ obesity, hypertension, dyslipidemias and cardiovascular disease (1-3). However, the basic mechanisms underlying insulin resistance are not known.

Skeletal muscle is the primary site of insulin stimulated glucose disposal at euglycemia $(4,5)$. Recently, a relationship between the fatty acid composition of skeletal muscle membrane structural lipid (phospholipid) and measures of insulin resistance have been demonstrated in both experimental animals and humans $(6-8)$. This has demonstrated that the greater the percentage of polyunsaturated fatty acids (PUFA) in muscle membranes, the better the insulin action. With the exception of some marine oils, dietary fats must be desaturated and elongated to become the long-chain PUFA of muscle membranes. The enzymes involved in these transformations, that we have focussed on in this paper, include: $\Delta 9$ desaturase, which inserts a double bond at the ninth carbon from the carboxyl terminal; $\Delta 5$ desaturase, which inserts a double bond at the fifth carbon from the carboxyl terminal; and the ubiquitous elongase enzyme, which inserts two carbon units at the carboxy terminal of the fatty acid (9). How these factors relate to insulin action or to body composition, which itself is related to insulin resistance, has not been fully explored.

There is an emerging body of evidence to suggest that dietary fat profile is a determining factor in weight gain and adiposity (10-13). Dietary fat content has been shown to act at the molecular level, having a direct effect on gene expression including both hepatic lipogenesis (14) and desaturase activity (15).

The present study was aimed at investigating the relationship between insulin action and adiposity and the structural lipid composition of the cell membrane. The results demonstrate that both impaired insulin action and obesity are independently associated with reduced $\Delta 5$ desaturase activity. In contrast, increased adiposity was additionally found to be associated with reduced elongase activity and higher $\Delta 9$ desaturase activity.

\section{Methods}

Subjects. Individuals in this study were 52 male volunteer Pima Indians of the Gila River Indian Community who were participating in a longitudinal study of the development of NIDDM (16). The metabolic studies were performed in the clinical research unit of the National Institutes of Health (NIH) in Phoenix, Arizona. Subjects were 44 years of age

1. Abbreviations used in this paper: $\mathrm{C} 20-22$ PUFA, the total percentage of long chain PUFA with $\geq 20$ carbon units; UI, the unsaturation index; LFPIns, log 10 fasting plasma insulin; $M$, low-dose in vivo insulin mediated glucose disposal rate; $\mathrm{MZ}$, high-dose in vivo insulin mediated glucose disposal rate; NIDDM, non-insulin-dependent diabetes mellitus; PUFA, polyunsaturated fatty acids. 
or younger and in good health as assessed by medical history and physical examination. The current analysis was limited to individuals with a mean fasting plasma glucose concentration of less than $7.8 \mathrm{mM}$. Subject characteristics are listed in Table I. All subjects gave informed consent, and the studies were approved by the ethics committees of the NIH, the Indian Health Service and the Gila River Indian Community.

Upon admission to the clinical research unit, all subjects received a weight maintenance diet consisting of $50 \%$ carbohydrate, $30 \%$ fat, and $20 \%$ protein. A 75 gram oral glucose-tolerance test was performed after $\geq 2 \mathrm{~d}$ on the diet and diabetes mellitus was diagnosed according to World Health Organization criteria (17). At this base-line test, glucose tolerance was normal in all but one subject who was marginally glucose intolerant. Body composition (pFAT) was estimated by hydrodensitometry with simultaneous determination of lung residual volume $(18,19)$.

Euglycemic clamp. In vivo insulin-mediated glucose disposal rate was measured by a two-step euglycemic-hyperinsulinemic clamp according to a modification of the method of DeFronzo et al. (20) which has been described previously (21). The clamp was performed by a primed continuous low- and high-dose insulin infusion (290 and 2900 $\mathrm{pmol} / \mathrm{min} \cdot \mathrm{m}^{2}$ respectively) each of which were continued for $100 \mathrm{~min}$ while the plasma glucose was maintained at $\sim 5.5 \mathrm{mmol} / \mathrm{liter}$. It is unlikely that a true "steady state" is obtained during this length of insulin infusion, although the glucose uptake approaches "steady state" after $60 \mathrm{~min}$. Nevertheless, the data does allow for relative comparisons between individuals to be made. The physiology for its own sake is not addressed and a pure "steady state" is not required for this analysis. The in vivo insulin action was determined during the period from 60 to $100 \mathrm{~min}$. Both the low-dose or physiological insulin stimulation level (M) and high-dose or maximal insulin stimulation level (MZ) use the units of $\mathrm{mg} / \mathrm{min} . \mathrm{kg}$ fat-free mass +17.7 (22). Plasma glucose was measured by the glucose oxidase method using a glucose analyzer (Beckman Instruments, Inc., Fullerton, CA) and insulin concentrations by radioimmunoassay using a radioassay analyzer (Concept 4 ; ICN, Horsham, PA).

Indirect calorimetry. $40 \mathrm{~min}$ before the initial insulin infusion and for the last $\mathbf{4 0} \mathrm{min}$ of each insulin infusion, oxygen consumption and carbon dioxide production were determined by open circuit indirect calorimetry (23).

Muscle biopsy. $2 \mathrm{~d}$ after the euglycemic hyperinsulinemic clamp, a percutaneous biopsy of the vastus lateralis muscle was obtained using a Bergström needle (Depuy, Phoenix, AZ). The specimen was immediately frozen and stored in liquid nitrogen for later analysis.

Phospholipid fatty acid analysis. Extraction and derivatization of the fatty acid components of muscle phospholipids has been described elsewhere (12). In brief, muscle tissue was homogenized in 2:1 (vol/ vol) chloroform:methanol and total lipid extracts prepared according to Folch et al. (24). Phospholipids were isolated from less polar lipids by solid-phase extraction on Sep-Pak silica cartridges (Waters, Milford, MA). The phospholipids were transmethylated and the methyl fatty acids separated, identified and quantitated by gas chromatography.

Fatty acid data analysis. The content of individual fatty acids in the skeletal muscle phospholipids was expressed as a percentage of the total fatty acids identified. (For a review on the nomenclature and function of the principal PUFA and their metabolic interconversions see references 25 and 26). Two fatty acid indices were derived from the primary data: the average degree of fatty acid unsaturation (the unsaturation index; UI), which was calculated as the average number of double bonds per fatty acid residue multiplied by 100 ; and the total percentage of long chain PUFA with $\geq 20$ carbon units (C20-22 PUFA). The activity of a number of the enzymes of fatty acid biosynthesis was estimated according to the product precursor ratios of the percentage of individual fatty acids. The estimated enzyme activities include: the ubiquitous elongase, calculated from the ratio of the percentage of 18:0 (stearic acid) to 16:0 (palmitic acid); and the $\Delta 5$ desaturase, calculated from the ratio of 20:4n-6 (arachidonic acid) to $20: 3 n-6$; and $\Delta 9$ desaturase, calculated from the ratio of $18: \ln -9$ (oleic acid) to $18: 0$.

Statistics. All data are expressed as the mean \pm SEM. All statistical analyses were performed using Statview 512+ statistical package (Aba-
Table I. Subject Characteristics

\begin{tabular}{lccc}
\hline \multicolumn{1}{c}{ Variable } & Mean* & Minimum & Maximum \\
\hline$n$ & 52 & & \\
Age (years) & $27.5 \pm 0.7$ & 18.1 & 43.8 \\
Height (cm) & $171.4 \pm 0.8$ & 150.5 & 182.5 \\
Weight (kg) & $96.8 \pm 4.0$ & 56.1 & 257.3 \\
Body Mass Index (wt/ht $\left.{ }^{2}\right)$ & $32.9 \pm 1.3$ & 19.0 & 81.2 \\
Percent body fat & $28 \pm 1$ & 14 & 53 \\
Waist/thigh (cm) & $1.7 \pm 0.1$ & 1.3 & 2.3 \\
Fasting plasma glucose (mM) & $5.0 \pm 0.1$ & 4.1 & 6.6 \\
Fasting plasma insulin (pM) & $215 \pm 15$ & 83 & 677 \\
Total M (mg/min.kgFFM + 17.7) & $3.3 \pm 0.2$ & 1.6 & 11.4 \\
Total MZ (mg/min.kgFFM + 17.7) & $9.0 \pm 0.3$ & 3.9 & 16.3 \\
& & &
\end{tabular}

*Values are mean $\pm \mathrm{SEM}$.

cus Concepts Inc., Berkeley, CA). The relations between variables were analyzed by both simple and multiple regression with significance determined by $\mathrm{F}$ value.

\section{Results}

Mean values and ranges obtained for body size and insulin action are shown in Table I. The group is an overweight population as indicated by the mean BMI and pFAT of $32.9 \pm 1.3$ and $28 \pm 1 \%$ respectively. The fatty acid profile of muscle phospholipids and correlations with fasting plasma insulin, clamp-derived $\mathrm{M}$ and $\mathrm{MZ}$ values, pFAT $\mathrm{BMI}$ and waist thigh ratio are listed in Table II. The relationships between the metabolic determinants and derived fatty acid indices are presented in Table III and the salient points are highlighted below.

Insulin action was significantly related to membrane phospholipid fatty acid proportions. This was true of measures of insulin action reflected by fasting insulin (LFPIns), glucose uptake at physiological insulin (M) or glucose uptake at supra physiological (MZ; maximally stimulating) insulin concentrations (Table III). Measures of insulin action were well correlated with each other and with measures of obesity (Table III). Similarly, measures of obesity were significantly correlated with each other and to membrane phospholipid fatty acid proportions. In contrast to these relationships, no significant relationships were observed between values for either basal lipid $(0.58$ $\pm 0.03 \mathrm{mg} / \mathrm{min} . \mathrm{kg} \mathrm{FFM}$; range $0.14-0.97$ ) or carbohydrate $(1.65 \pm 0.07 \mathrm{mg} / \mathrm{min} . \mathrm{kg}$ FFM; range $0.70-3.10)$ oxidation and any measure of insulin action or obesity.

Insulin action and fatty acid variables. As shown in Table III, significant correlations were found between $\mathrm{MZ}$ and: $(a)$ the percentage of C20-22 PUFA; $(b) \Delta 5$ desaturase activity; and $(c)$ the composite measure of unsaturation, UI. Similarly, insulin action at the low dose insulin infusion $(M)$ was also positively correlated with the percentage of C20-22 PUFA and $\Delta 5$ desaturase activity (Fig. $1 a$ ) but not UI.

Obesity and fatty acid variables. A number of individual fatty acids and derived indices were significantly correlated with measures of adiposity (Tables II and III). The $\Delta 5$ desaturase activity, related strongly to measures of adiposity (Fig. $1 b$ ) as did the ratio 18:0/16:0, an index of elongase activity (Fig. 2). Furthermore, a significant $(P<0.05)$ relationship was observed 
Table II. The Profile of Fatty Acids in the Phospholipid Fraction of Skeletal Muscle and Simple Correlations with Fasting Plasma Insulin, Insulin Action Indices, Percentage Body Fat, Body Mass Index and Waist to Thigh Ratio

\begin{tabular}{|c|c|c|c|c|c|c|c|}
\hline Variable & Mean* & LFPIns $^{\ddagger}$ & $\log M^{3}$ & Log $M Z^{\|}$ & $\mathrm{pFAT}^{4}$ & BMI** & Waist/thigh \\
\hline $16: 0$ & $15.3 \pm 0.2$ & 0.156 & -0.009 & -0.094 & $0.334^{\mathrm{a}}$ & $0.320^{\mathrm{a}}$ & 0.153 \\
\hline 18:0 & $13.1 \pm 0.2$ & -0.092 & 0.273 & 0.117 & $-0.286^{\mathrm{a}}$ & $-0.288^{\mathrm{a}}$ & -0.168 \\
\hline $16: 1$ & $1.2 \pm 0.1$ & $0.304^{a}$ & -0.263 & -0.207 & 0.145 & 0.201 & 0.115 \\
\hline $18: \ln 9$ & $7.9 \pm 0.2$ & 0.062 & -0.147 & 0.065 & 0.251 & 0.189 & 0.156 \\
\hline $18: 2 n-6$ & $36.2 \pm 0.3$ & 0.199 & -0.201 & $-0.297^{\mathrm{a}}$ & 0.069 & 0.121 & 0.149 \\
\hline $20: 3 n-6$ & $2.0 \pm 0.0$ & $0.444^{c}$ & $-0.479^{c}$ & -0.266 & $0.587^{d}$ & $0.528^{d}$ & $0.400^{b}$ \\
\hline $20: 4 n-6$ & $16.8 \pm 0.2$ & $-0.416^{\mathrm{b}}$ & $0.292^{\mathrm{a}}$ & $0.391^{\mathrm{b}}$ & $-0.322^{\mathrm{a}}$ & $-0.348^{\mathrm{b}}$ & -0.132 \\
\hline $22: 5 n-6$ & $1.0 \pm 0.1$ & $-0.299^{\mathrm{a}}$ & 0.254 & $0.314^{\mathrm{a}}$ & -0.024 & -0.081 & $-0.401^{b}$ \\
\hline $22: 6: n-3$ & $1.3 \pm 0.1$ & -0.101 & 0.112 & 0.119 & -0.254 & $-0.306^{a}$ & $-0.298^{a}$ \\
\hline
\end{tabular}

* Values are means \pm SEM expressed as a percentage of total fatty acids. ${ }^{\ddagger} \log 10$ of the fasting plasma insulin (pM). ${ }^{8} \log 10$ of the low-dose insulin- $\left(290 \mathrm{pmol} / \mathrm{min} \cdot \mathrm{m}^{2}\right)$ mediated glucose disposal rate $(\mathrm{mg} / \mathrm{min} / \mathrm{kgFFM}+17.7)$. " $\mathrm{Log} 10$ of the high-dose insulin- $\left(2900 \mathrm{pmol} / \mathrm{min} . \mathrm{m}^{2}\right) \mathrm{mediated}$ glucose disposal rate $(\mathrm{mg} / \mathrm{min} / \mathrm{kgFFM}+17.7)$. ' Percentage body fat determined by densitometry. ${ }^{* *}$ Body mass index $\left(\mathrm{wt}^{\mathrm{k}} / \mathrm{t}^{2}\right){ }^{\mathrm{a}} P<0.05 ;{ }^{\mathrm{b}} P$ $<0.01 ;{ }^{\mathrm{c}} P<0.001 ;{ }^{\mathrm{d}} P<0.0001$.

between percentage body fat and $\Delta 9$ desaturase activity $(18: 1 \mathrm{n}-$ 9/18:0).

Insulin action and obesity. Measures of insulin action were related to each other as well as to measures of obesity (Table III). $\Delta 5$ desaturase activity was the only lipid variable that correlated with all the measures of insulin action and all the obesity measures (Table III).

Table IV shows possible permutations of the independent relationships between $\Delta 5$, insulin action and adiposity. $\Delta 5$ related to LFPIns, $\mathrm{M}$ and $\mathrm{MZ}$ independent of pFAT, BMI and waist/thigh. In turn, $\Delta 5$ related to $\mathrm{pFAT}$ and BMI but not waist thigh ratio, independently of all three measures of insulin action.

The C20-22 PUFA and UI were related to insulin action but not to any direct measure of adiposity or central adiposity (Table III). On the other hand elongase and $\Delta 9$ were significantly related to BMI and pFAT but not at all to insulin action (Table III).

\section{Discussion}

The present study has demonstrated significant relationships between skeletal muscle membrane phospholipid fatty acid composition and both insulin action and adiposity in a population with the highest reported incidence of NIDDM in the world. Diabetes mellitus in this discrete population has been extensively characterized and roles for obesity, insulin receptor and post receptor function, insulin resistance, family history and genetic make-up in NIDDM have been determined (16, 2733 ). The initial lesion that leads to diabetes in this population appears to be insulin resistance in skeletal muscle and possibly liver. The current studies relating obesity, insulin action and membrane phospholipid were performed in a search for possible underlying mechanisms for these previous clinical observations. These studies extend earlier findings in Caucasians showing relationships between insulin action and skeletal muscle membrane lipid composition $(7,8)$. The present data are unable to define the cause for this insulin resistance or the effect of obesity on insulin resistance. However, since membrane function is central to most physiological processes, the current findings have far reaching implications for possible causes of diabetes and obesity.

Cell membranes are dynamic lipid bilayers which separate the cell from the extracellular milieu and surround intracellular organelles. The major component is phospholipid which consti-

Table III. Correlation Table of Metabolic Determinants and Derived Fatty Acid Indices

\begin{tabular}{|c|c|c|c|c|c|c|c|c|c|c|c|c|}
\hline Variable & Mean* & LFPIns $^{\ddagger}$ & $\log M^{3}$ & $\log M Z^{\|}$ & pFAT $^{9}$ & BMI** & Waist/thigh & UI & $\mathrm{C} 20-22$ & Elongase & $\Delta 9$ & $\Delta 5$ \\
\hline LFPIns & $2.3 \pm 1.1$ & 1 & & & & & & & & & & \\
\hline $\log M$ & $0.45 \pm 0.02$ & $-0.788^{d}$ & 1 & & & & & & & & & \\
\hline $\log M Z$ & $0.92 \pm 0.01$ & $-0.854^{d}$ & $0.789^{d}$ & 1 & & & & & & & & \\
\hline pFAT & $28 \pm 1$ & $0.649^{d}$ & $-0.558^{\mathrm{d}}$ & $-0.458^{\mathrm{c}}$ & 1 & & & & & & & \\
\hline BMI & $32.9 \pm 1.3$ & $0.557^{\mathrm{d}}$ & $-0.447^{b}$ & $-0.408^{b}$ & $0.879^{d}$ & 1 & & & & & & \\
\hline Waist/thigh & $1.7 \pm 0.2$ & $0.555^{\mathrm{d}}$ & $-0.471^{\mathrm{c}}$ & $-0.490^{c}$ & $0.572^{\mathrm{d}}$ & $0.579^{d}$ & 1 & & & & & \\
\hline Unsaturation index & $176.6 \pm 0.9$ & $-0.371^{b}$ & 0.214 & $0.369^{b}$ & -0.187 & $-0.306^{\mathrm{a}}$ & -0.193 & 1 & & & & \\
\hline C20-22 polyunsaturated & $22.7 \pm 0.3$ & $-0.396^{b}$ & $0.296^{\mathrm{a}}$ & $0.463^{c}$ & -0.169 & $-0.284^{\mathrm{a}}$ & -0.245 & $0.839^{d}$ & 1 & & & \\
\hline Elongase activity (18:0/16:0) & $0.85 \pm 0.0$ & -0.170 & 0.190 & 0.137 & $-0.467^{\mathrm{c}}$ & $-0.422^{b}$ & -0.240 & 0.129 & 0.069 & 1 & & \\
\hline$\Delta 9$ activity $(18: 1 \mathrm{n}-9 / 18: 0)$ & $0.63 \pm 0.0$ & -0.108 & -0.219 & -0.008 & $0.332^{\mathrm{a}}$ & $0.275^{\mathrm{a}}$ & 0.223 & -0.032 & -0.079 & $-0.592^{\mathrm{d}}$ & 1 & \\
\hline$\Delta 5$ activity $(20: 4 n-6 / 20: 3 n-6)$ & $8.02 \pm 0.2$ & $-0.589^{d}$ & $0.563^{d}$ & $0.451^{\mathrm{c}}$ & $-0.610^{d}$ & $-0.576^{d}$ & $-0.348^{b}$ & $0.421^{b}$ & $0.351^{\mathrm{b}}$ & $0.365^{b}$ & $-0.341^{2}$ & 1 \\
\hline
\end{tabular}

Mean values are means \pm SEM. Other values as described in Table II ${ }^{\mathrm{a}} P<0.05 ;{ }^{\mathrm{b}} P<0.01 ;{ }^{\mathrm{c}} P<0.001 ;{ }^{\mathrm{d}} P<0.0001$. 


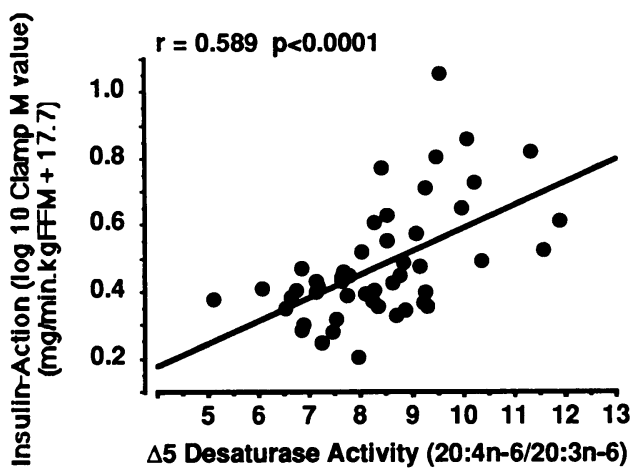

b

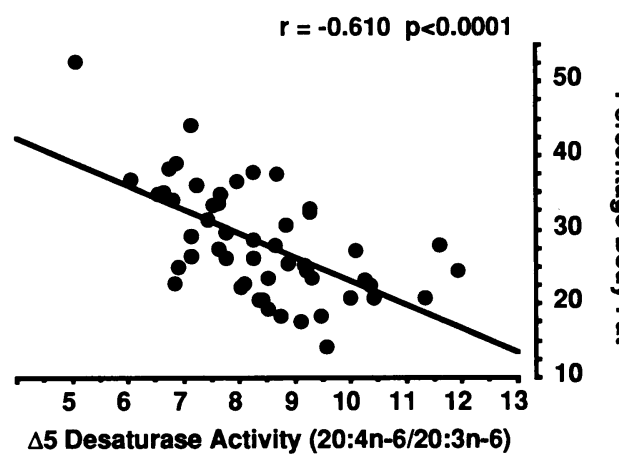

Figure 1. Insulin-action ( $\mathrm{M} ; a$ ) and percentage body fat $(b)$ in relation to $\Delta 5$ desaturase activity. The index of insulin-action at physiological insulin level (M; $290 \mathrm{pmol} / \mathrm{min} \cdot \mathrm{m}^{2}$ ) was derived from the hyperinsulinemic euglycemic clamp technique and is expressed in terms of the number of milligrams of glucose infused per minute per $\mathrm{kg}$ of fat free mass + 17.7. Percentage body fat was determined by hydrodensitometry. $\Delta 5$ desaturase activity was estimated according to the fatty acid product precursor ratio $20: 4 n-6 /$ $20: 3$ n-6. tutes $\sim 60 \%$ of the plasma membrane and $>90 \%$ of some organelle membranes such as mitochondria (34). Membranes permit the maintenance of ionic gradients, potential differences and modulate the passage of hormones, substrates, nutrients and intracellular signals. As such, the fatty acid composition of membrane phospholipids themselves are instrumental determinants of cellular metabolism. The current studies used total muscle membranes. Isolation of subcellular membrane fraction would doubtless provide even greater insight into the role of membranes in insulin action and obesity.

NIDDM is a genetic disease that becomes manifest under particular environmental conditions $(27-30,35,36)$. The environmental component of NIDDM is demonstrated by the secular trends in diabetes prevalence this century, particularly in developing societies $(37,38)$. Obesity has long been associated with the development of NIDDM and along with diet composition, may constitute one of the major "environmental" determinants of the development of the disease. The incidence of NIDDM in the Pima Indians is proportional to the degree of obesity as well as the family history of the disease (27) consistent with environmental and genetic causes. Obesity also correlates with the degree of insulin resistance and it seems possible that the impact of obesity on NIDDM may be mediated via insulin resistance $(22,33)$. Membrane lipid composition has the potential to be influenced by both genetic and lifestyle factors and therefore may be the focal point at which these factors act in concert to determine insulin action. This could also be true for

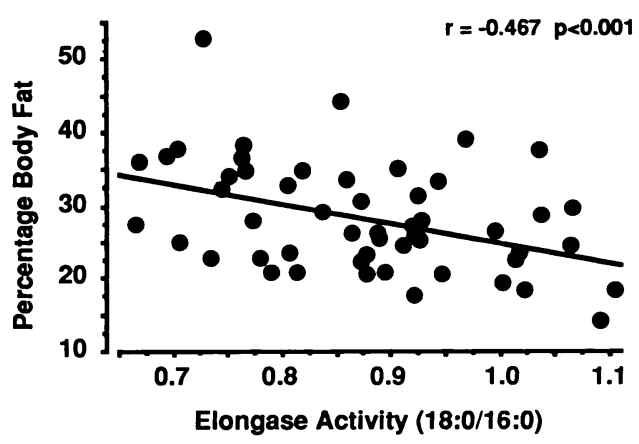

Figure 2. Percentage body fat in relation to elongase activity. Elongase activity was estimated from the product precursor ratio of the percentages of individual fatty acids 18:0/16:0. example if the activities of the enzymes controlling the formation of long-chain PUFA or their insertion into the structural lipids of cell membranes, were under strong genetic influence. In addition, dietary lipid profile (12, 39-41) and alcohol (42) are environmental factors capable of modifying membrane lipid composition.

With the exception of certain marine oils, the major dietary fatty acids must all be substantially elongated and desaturated to be transformed into the long chain PUFA that we have shown to be associated with leanness and insulin sensitivity. In this study, enzyme activities were determined indirectly by product precursor ratios. A strong relationship was observed between reduced $\Delta 5$ desaturase activity (20:4n-6/20:3n-6) and both reduced insulin action and increased adiposity. Both insulin action and obesity are independently related to $\Delta 5$ and both obesity and $\Delta 5$ independently correlate with $M$ values. This means that the strong relationship of the $\Delta 5$ to insulin resistance is not merely an epiphenomenon of the effects of obesity and therefore deserves consideration as part of the genetic predisposition to insulin resistance (28). On the other hand, the C20-22 PUFA and UI independently correlate with measures of insulin action but not obesity. This could be due to effects of either genotype or diet directly on insulin action.

The elongase activity (18:0/16:0), which inserts two carbon units onto the fatty acid backbone, showed a relationship to obesity but not to insulin action. The elongase enzyme is thought to be ubiquitous throughout all fatty acid biosynthetic pathways and it must work in concert with the desaturase enzymes as requisite steps between the major dietary n- 6 and n3 fatty acids (linoleic and $\alpha$-linolenic) and the formation of the important long chain PUFA.

$\Delta 9$ desaturase, which inserts a double bond at carbon nine of the fatty acid chain, was also associated with obesity but not insulin action. This is a novel finding in humans but entirely consistent with results in animal models of obesity (13). Though the etiological significance of increased $\Delta 9$ desaturase activity in obesity is unclear it may relate to an attempt to compensate for major decreases in other desaturase enzymes in order to maintain cell membrane fluidity within some regulated range. Certainly there is clear evidence for major (and uncharacteristic) increases in the $n-9$ class of fatty acids during essential (n-6 and/or n-3) fatty acid deficiencies $(43,44)$. Studies aimed at measuring enzyme activity before and after intervention (resulting in both weight loss or weight gain) would be instructive 
in elucidating whether altered $\Delta 9$ or desaturase activities are the likely cause or effect in adiposity.

The results indicate that some aspects of fatty acid metabolism are of considerable importance in the well recognized obesity-insulin action relationship while others are not. This is consistent with the observations that insulin action has determinants that are independent of obesity (28) and that obesity bears a complex relationship with insulin resistance (45).

Given the relationships between adiposity and phospholipid biosynthetic enzyme activities what are the possible mechanisms which might subtend such relationships? Increases in ion "leakage" and $\mathrm{Na}^{+} / \mathrm{K}^{+}$ATPase activity, (i.e., increased whole-body metabolic rate) have been directly associated with increased PUFA content in comparative studies between endotherms and ectotherms $(46,47)$. In animals and humans, increasing the dietary polyunsaturated to saturated ratio resulted in increased membrane unsaturation $(12,41)$ and increased basal metabolic rate $(10,26)$. The effect of leaking membranes may not be limited to energy expenditure. Leaking membranes are the basis of spontaneous membrane depolarization which may affect neuronal firing rates and in turn muscle gene expression affecting muscle fibre type $(48,49)$. Altered ion flux may also influence central nervous system activity and hence the regulation of numerous processes including appetite.

The overall control of the partitioning of dietary fats between storage and oxidation is not clear. However, work in rodents has shown very clear differences between the oxidation rates of different fatty acids (50). Longer-chain PUFA are oxidized at much faster rates than are saturated fats. Alteration in enzyme activities, as are here associated with obesity, would favor an increased proportion of the less readily oxidized fatty acids, and thus may cause, or at least exacerbate, the tendency towards decreased fat oxidation in the obese. This study found no relationship between lipid oxidation rate and phospholipid fatty acid composition. This may reflect the fact that most of the lipid for oxidation is coming from storage triglyceride and the relationship of its fatty acid profile to that of muscle membrane phospholipid is unknown.

Docosahexaenoic acid (22:6n-3) is the most highly unsaturated and longest chain of any fatty acid found in skeletal muscle. It comprises the bulk proportion of total n-3 fatty acids. Unless provided in the diet (primarily as marine oils), its precursors must be substantially elongated and desaturated to form this fatty acid. One striking difference between the muscle phospholipid fatty acid composition in the Pima Indians and an Australian, largely Caucasian, population (7) is the low percentage of long chain n-3 PUFA (22:6n-3: $1.2 \pm 0.1 \%$ versus $2.5 \pm 0.7 \%$ in the Australian population). This finding may reflect a very low dietary intake of $n-3$ in the Pima Indians. However, among the Australian population even individuals with little or no discernible n-3 intake (unpublished observations) had muscle membrane $\mathrm{n}-3$ levels much higher than the Pima study group. The low levels of $n-3$ in the Pimas may then reflect a genetic reluctance to incorporate this important class of fatty acids into membranes, thus predisposing this population to the "syndromes of insulin resistance." Further to this point, an intestinal fatty acid binding protein loci on chromosome $4 \mathrm{q}$ has been significantly linked with insulin resistance in Pima Indians (32). It is tempting to speculate that the "thrifty gene (s)" $(51,52)$ may therefore include, those which control the binding and uptake of certain fatty acids, the incorporation of specific PUFA into membrane lipids, and/or regulation of 
the production and activity of the enzymes that elongate and desaturate fatty acids.

This study is unable to determine which are the cause and effects in any of the relationships described. The possibility that $\Delta 5$ desaturase activity could be part of the genetic regulation of insulin resistance needs to be explored. Whether any effect of diet on insulin resistance could be mediated through this enzyme or the fatty acid levels it regulates deserves study. Finally, it is possible that obesity directly affects elongase and $\Delta 9$ desaturase activity, but it should also be considered that such alterations of activity might lead to obesity.

\section{Acknowledgments}

Supported by the National Health and Medical Research Council of Australia, the Grains Research and Development Corporation, the Rebecca L Cooper Foundation, the Diabetes Australia Research Trust and the research and development program established by Beecham (Australia) Pty. Ltd. under the Pharmaceutical Industry Development Progiam. We are indebted to the staff members of the National Institutes of Health in the Gila River Indian Community and the residents and leaders of that community, for their co-operation and assistance.

\section{References}

1. Reaven, G. M. 1988. Role of insulin resistance in human disease. Diabetes. 37:1595-1607

2. Reaven, G. M. 1993. Role of insulin resistance in human disease (Syndrome $\mathrm{X})$ : an expanded definition. Ann. Rev. Med. 44:121-131.

3. Bjürntorp, P. 1991. Visceral fat accumulation: the missing link between psychosocial factors and cardiovascular disease? J. Int. Med. 230:195-201.

4. DeFronzo, R. A., E. Jacot, E. Jequier, J. Wahren, and J. P. Felber. 1981.

The effect of insulin on the disposal of intravenous glucose: results from indirect calorimetry and hepatic and femoral venous catheterization. Diabetes. 30:10001007.

5. Shulman, G. I., D. L. Rothman, T. Jue, P. Stein, R. A. DeFronzo, and R. G. Shulman. 1990. Quantitation of muscle glycogen synthesis in normal subjects and subjects with non-insulin-dependent diabetes by ${ }^{13} \mathrm{C}$ nuclear magnetic resonance spectroscopy. N. Engl. J. Med. 322:223-228.

6. Storlien, L. H., A. B. Jenkins, D. J. Chisholm, W. S. Pascoe, S. Khouri, and E. W. Kraegen. 1991. Influence of dietary fat composition on development of insulin resistance in rats. Relationship to muscle triglyceride and $\omega-3$ fatty acids in muscle phospholipids. Diabetes. 40:280-289.

7. Borkman, M., L. H. Storlien, D. A. Pan, A. B. Jenkins, D. J. Chisholm, and L. V. Campbell. 1993. The relationship between insulin sensitivity and the fatty acid composition of phospholipids of skeletal muscle. N. Engl. J. Med. 328:238-244.

8. Vessby, B., S. Tengblad, and H. Lithell. 1994. Insulin sensitivity is related to the fatty acid composition of serum lipids and skeletal muscle phospholipids in 70-year-old men. Diabetologia. 37:1044-1050.

9. Jeffcoat, R. 1979. The biosynthesis of unsaturated fatty acids and its control in mammalian liver. Essays Biochem. 15:1-36.

10. Jones, P. J. H., and D. A. Schoeller. 1988. Polyunsaturated:saturated ratio of diet fat influences energy substrate utilization in the human. Metabolism. 37:145-151.

11. Cunnane, S. C., K. R. Mc Adoo, and D. F. Horrobin. 1986. n-3 essential fatty acids decrease weight gain in genetically obese mice. Br. J. Nutr. 56:8795.

12. Pan, D. A., and L. H. Storlien. 1993. Dietary lipid profile is a determinant of tissue phospholipid fatty acid composition and rate of weight gain in rats. $J$. Nutr. 123:512-519.

13. Pan, D. A., A. J. Hulbert, and L. H. Storlien. 1994. Dietary fats, membrane phospholipids and obesity. J. Nutr. 124:1555-1566.

14. Clarke, S. D., and D. B. Jump. 1993. Regulation of gene transcription by polyunsaturated fatty acids. Prog. Lipid Res. 32:139-149.

15. Ntambi, J. M. 1992. Dietary regulation of stearoyl-CoA desaturase 1 gene expression in mouse liver. J. Biol. Chem. 267:10925-10930.

16. Lillioja, S., D. M. Mott, M. Spraul, R. Ferraro, J. E. Foley, E. Ravussin W. C. Knowler, P. H. Bennett, and C. Bogardus. 1993. Insulin resistance and insulin secretory dysfunction as precursors of non-insulin-dependent diabetes mellitus. N. Engl. J. Med. 329:1988-1992.

17. WHO Study Group. 1985. Diabetes Mellitus, WHO Technical Report Series No. 727.
18. Goldman, R. F., and E. R. Buskirk. 1961. A method for underwater weighing and the determination of body density. In Techniques for measuring body composition. J. Brozek and A. Herschel, editors. Natl Acad Sci Natl Res Council, Washington DC. 78-106

19. Keys, A., and J. Brozek. 1953. Body fat in adult man. Physiol Rev. 33:245-325.

20. DeFronzo, R. A., J. D. Tobin, and R. Andres. 1979. Glucose clamp technique: a method for quantifying insulin secretion and resistance. Am. J. Phys iol. 237:E214-E223.

21. Lillioja, S., C. Bogardus, D. M. Mott, A. L. Kennedy, W. C. Knowler, and B. V. Howard. 1985. Relationship between insulin-mediated glucose disposal and lipid metabolism in man. J. Clin. Invest. 75:1106-1115.

22. Lillioja, S., and C. Bogardus. 1987. Obesity and insulin resistance: lessons learned from the Pima Indians. Diabetes Metab. Rev. 4:517-540.

23. Lillioja, S., J. Foley, C. Bogardus, D. Mott, and B. V. Howard. 1986. Free fatty acid metabolism and obesity in man: in vivo in vitro comparisons. Metabolism. 35:505-514.

24. Folch, J., M. Lees, and G. H. Sloane Stanley. 1957. A simple method for the isolation and purification of total lipids from animal tissues. J. Biol. Chem. 226:497-509.

25. Stubbs, C., and A. Smith. 1984. The modification of mammalian membrane polyunsaturated fatty acid composition in relation to membrane fluidity and function. Biochim. Biophys. Acta. 779:89-137.

26. Pan, D. A., and L. H. Storlien. 1993. Effect of dietary lipid profile on the metabolism of $\omega-3$ fatty acids: implications for obesity prevention. In Omega-3 fatty acids: Metabolism and biological effects. C. A. Drevon, I. Baksaas, and H. E. Krokan, editors. Birkhàuser Verlag, Basel. 97-106

27. Knowler, W. C., D. J. Pettitt, P. J. Savage, and P. H. Bennett. 1981 Diabetes incidence in Pima Indians: contributions of obesity and parental diabetes. Am. J. Epidemiol. 113:144-156.

28. Lillioja, S., D. M. Mott, J. K. Zawadzki, A. A. Young, W. G. H. Abbott, W. C. Knowler, P. H. Bennett, P. Moll, and C. Bogardus. 1987. In vivo insulin action is familial characteristic in nondiabetic Pima Indians. Diabetes. 36:1329_ 1335.

29. Knowler, W. C., P. H. Bennet, R. F. Hamman, and M. M. 1978. Diabetes incidence and prevalence in Pima Indians: a 19-fold greater incidence than in Rochester, Minnesota. Am. J. Epidemiol. 108:497-505.

30. Knowler, W. C., R. C. Williams, D. J. Pettitt, and A. G. Steinberg. 1988. $\mathrm{Gm}^{3: 5.13,14}$ and type 2 diabetes mellitus: an association in American Indians with genetic admixture. Am. J. Hum. Genet. 43:520-526.

31. Lillioja, S., D. M. Mott, B. V. Howard, P. H. Bennett, H. Yki-Jàrvinen, D. Freymond, B. L. Nyomba, F. Zurlo, B. Swinburn, and C. Bogardus. 1988 Impaired glucose tolerance as a disorder of insulin action: longitudinal and crosssectional studies in Pima Indians. N. Engl. J. Med. 318:1217-1225.

32. Prochazka, M., S. Lillioja, J. F. Tait, W. C. Knowler, D. M. Mott, M. Spraul, P. H. Bennett, and C. Bogardus. 1993. Linkage of chromosomal markers on $\mathbf{4 q}$ with a putative gene determining maximal insulin action in Pima Indians. Diabetes. 42:514-519.

33. Lillioja, S., and C. Bogardus. 1988. Insulin resistance in Pima Indians. Acta Med. Scand. Suppl. 723:103-119.

34. McMurchie, E. J. 1988. Dietary lipids and the regulation of membrane fluidity and function. In Physiological Regulation of Membrane Fluidity. R. C. Aloia, editors. Alan R Liss Inc., New York. 189-237

35. Barnett, A. H., C. Eff, R. D. G. Leslie, and D. A. Pyke. 1981. Diabetes in identical twins: a study of 200 pairs. Diabetologia. 20:87-93.

36. Gottlieb, M. S., and H. F. Rott. 1968. Diabetes mellitus in twins. Diabetes. 17:693-704

37. Mather, H. M., and H. Keen. 1985. The Southall Diabetes Survey: prevalence of diabetes in Asians and Europeans. Br. Med. J. 291:1081-1084.

38. Taylor, R., and P. Zimmet. 1983. Epidemiology of diabetes: migrant studies. In Diabetes in epidemiological perspective. J. I. Mann, K. Pyorala, and A. Teuscher, editors. Churchill Livingstone, New York. 58-77

39. Beynen, A. C., R. J. J. Hermus, and J. G. A. J. Hautvast. 1980. A mathematical relationship between the fatty acid composition of the diet and that of the adipose tissue in man. Am. J. Clin. Nutr. 33:81-85.

40. Dayton, S., S. Hashimoto, W. Dixon, and M. L. Pearce. 1966. Composition of lipids in human serum and adipose tissue during prolonged feeding of a diet high in unsaturated fat. J. Lipid Res. 7:103-111.

41. McMurchie, E. J., B. M. Margetts, L. J. Beilin, K. D. Croft, R. Vandongen, and B. K. Armstrong. 1984. Dietary-induced changes in the fatty acid composition of human cheek cell phospholipids: correlation with changes in the dietary polyunsaturated/saturated fat ratio. Am. J. Clin. Nutr. 39:975-980.

42. Nakamura, M. T., A. B. Tang, J. Millanueva, C. H. Jalsted, and S. D. Phinney. 1994. Selective reduction of $\Delta 6$ and $\Delta 5$ desaturase activities but not $\Delta 9$ desaturase in micropigs chronically fed ethanol. J. Clin. Invest. 93:450-454.

43. Paulsrud, J. R., L. Pensler, C. F. Whitten, S. Stewart, and R. T. Holman. 1972. Essential fatty acid deficiency in infants induced by fat-free intravenous feeding. Am. J. Clin. Nutr. 25:897-904. 
44. Mohrhauer, H., and R. T. Holman. 1963. The effect of dose level of essential fatty acids upon fatty acid composition of the rat liver. J. Lipid Res. 4:151-159.

45. Swinburn, B. A., B. L. Nyomba, M. F. Saad, F. Zurlo, I. Raz, W. C Knowler, S. Lillioja, C. Bogardus, and E. Ravussin. 1991. Insulin resistance associated with lower rates of weight gain in Pima Indians. J. Clin. Invest. 88:168173

46. Else, P. L., and A. J. Hulbert. 1987. Evolution of mammalian endothermic metabolism: "leaky" membranes as a source of heat. Am. J. Physiol. 253:R1R7.

47. Brand, M. D., P. Couture, P. L. Else, K. W. Withers, and A. J. Hulbert 1991. Evolution of energy metabolism. Proton permeability of the inner membran of liver mitochondria is greater in mammal than in a reptile. Biochem. J. 275:8186.
48. Saltin, B., and P. D. Gollnick. 1983. Skeletal muscle adaptability, significance of metabolism and performance. In Handbook of physiology. Skeletal muscle. L. D. Peachy, editors. American Physiology Society, Bethesda, MD. 555631

49. Eisenburg, B. R. 1983. Quantitative ultrastructure of mammalian skeletal muscle. In Handbook of physiology. Skeletal muscle. L. D. Peachy, editors. American Physiological Society, Bethesda MD. 73-111

50. Leyton, J., P. J. Drury, and M. A. Crawford. 1987. Differential oxidation of saturated and unsaturated fatty acids in vivo in the rat. Br J. Nutr. 57:383393.

51. Neel, J. V. 1962. Diabetes mellitus: a "thrifty" genotype rendered detrimental by "progress." Am J Human Genetics. 14:353-362.

52. Ravussin, E., and C. Bogardus. 1990. Energy expenditure in the obese: is there a thrifty gene? Infusiostherapie. 17:108-112. 